\title{
THE ESTIMATION OF INSOLUBLE FATTY ACIDS.
}

\section{By Charles E. Cassau.}



THE use of a filter in the process of washing insoluble fatty acids in the analysis of butter and other fats is cumbrous and presents numerous and obvious sources of error. In carrying out this estimation I have for several years employed a form of separator which renders the use of a filter paper quite unnecessary, and at the same time enables the washing to be done in a far more thorough and satisfactory manner. In the form in which it was originally used, the separator was a pearshaped vessel of rather thick glass, provided with a tapped tube with a narrow bore; but the apparatus that $I$ have used for some years past is globular, is made of thin glass, will stand boiling water, and is provided with a tap and tube of wider bore, the end of the tube being cut off at an angle. The older form was more liable to break, and did not always allow of the fatty acids being obtained in a thin layer, which is, in many respects, a great advantage; nor of the greater part of the acids being easily removed from the apparatus without the aid of a solvent.

In using the apparatus, the soap obtained from any convenient weight of fat, but preferably from about five grammes, is poured into strong hydrochloric acid previously introduced into the separator, the residual soap being washed in through a funnel with boiling water. 
The resulting fatty acids are washed with successive small quantities of boiling water, the globe of the separator being about half-filled each time. After the decomposition it is necessary to allow the mixture to stand; the major portion of the insoluble acids appear, of course, as an oily layer on the surface of the liquid, but a very marked proportion is distributed through the latter and makes it more or less turbid. Hence it is convenient so to time the work as to allow of the first mixture standing over night. This always ensures complete separation, and subsequent washing does not reproduce the turbidity. The washing being completed, the last wash-water is run off, and the insoluble fatty acids, which are, of course, in a liquid state, are received directly into a weighed vessel, preferably a deep and light platinum basin. The portions adhering to the sides of the apparatus are then washed down with ether, the latter evaporated, and the acids dried to constant weight. The apparatus will be found useful for several other operations.

Three other papers were postponed owing to the lateness of the hour.

The meeting then adjourned to the Criterion Restaurant, where the Annual Dinner of the Society was held. About fifty members and friends assembled. The chair was occupied by the newly-elected President, Sir Charles Cameron, supported by-Mr. Otto Hehner (past President), Dr. James Bell, C.B., F.R.S., Captain Verney Cameron C.B., R.N., Dr. F. Allan, Surgeon-Major Carte, Dr. Cory, Dr. Abraham, Surgeon-Captain Jackson, Dr. Kennedy, Mr. A. H. Allen, Mr. C. E. Cassal, Dr. Sykes, Mr. E. W. Voelcker, Mr. R. H. Davies (Hon. Sec.), Dr. Bernard Dyer (Hon. Sec.), Mr. Aubrey Rake (Solicitor to the Society), \&c.

The Chairman proposed the toast of the Queen, the Prince and Princess of Wales, and the rest of the Royal Family; and that of the Navy, Army and Reserve Forces, the former being responded to by Captain Cameron. Surgeon-Major Carte replied for the Army, and Captain Cassal for the Reserve Forces.

The Chairman proposed the toast of the evening : "The Society of Public Analysts," coupled with the name of Mr. Otto Hehner, ex-President, to whom he referred in very flattering terms.

Mr. Hehner said the Society had for seventeen years worked very hard for the welfare of the community under circumstances which would have disheartened most other people. When, twenty-one years ago, the Adulteration Act of 1872 was passed, and the fiat went forth that there should be a body of gentlemen appointed as Public Analysts, there were no practical means of carrying out the requirements of the Act, and although they were asked to make analyses of foods and drinks they had practically no means of doing so. They knew now that twenty-one years ago they were intensely ignorant, and knew nothing of such matters as milk, butter, bread, and drugs; but the Society had laboured year after year in connection with these subjects, and members from all corners of the country had read a great many papers. They were, he thought, in a far 
better position now than they were before. In the seventeen years the Society had existedits members had read 450 papers on every possible subject of their work, and, besides that, 150 papers had been published by members in the Society's Journal. This constituted a mine of information for all those who worked in that direction, and especially for Analysts all over the world, for this country was the first to take action in the matter, and the Legislatures of other countries had followed its lead. Seventeen years ago 20 per cent. of the articles analysed were adulterated, now the percentage was about 11 . As to the quantity of adulteration then practised, it was appalling-milk would be found to have 50 per cent. of added water; bread had any amount of alum in it; and spirits were watered to any extent. Now, however, there was a general decline in adulteration, and thus the Public Analyst had saved the public millions of pounds, and inasmuch as the larger portion of the Nation's earnings were spent in food, the importance of their work was manifest. But as the Analysts had made advances in knowledge, so had the enemies of the purity of food, and it must be remembered that while the former worked in the light, the latter worked in secret, and had taken such advantage of the increase of knowledge, that at the present time, more than at any other time in the history of the world, adulteration was practised as a fine art. There was, therefore, still 'plenty of work for Public Analysts to do in coping with scientific adulteration.

Mr. Alfred H. Allen proposed the next toast, the health of the President, Sir Charles Cameron, who, he said, was the senior Public Analyst of the United Kingdom, he having been appointed under the Act of 1860, which was then only a Permissive Act. They might fairly say that Sir Charles had a longer experience of the working of the Adulteration Act than any Analyst now living, and they had, therefore, every reason to regard him as their father so far as experience went in these matters, and as such they cordially welcomed him to the Presidential Chair.

The President in response, referred to his experience as a Public Analyst during the last thirty-one years, and contrasted the conditions under which he had to work during the first part of that period with the altered circumstances of recent years. There was then very little to guide Public Analysts, and there was no awful tribunal at Somerset House to overrule them. So far as Dublin was concerned at the present time, there was hardly anything in the way of ordinary articles of food adulterated, with the exception of butter and milk. With regard to flour, bread, coffee, confectionery, etc., they were formerly adulterated to an enormous extent, but it would be impossible now, he thought, to find any of these things in a sophisticated state in his city. In concluding, Sir Charles referred with satisfaction to the honour that had been done the country he represented, by the fact that quite recently he had not only been appointed President of that Society, but also President of the Sanitary Institute of Great Britain and Ireland, and also of the Institute of Public Health, of which his friends, Dr. Allan and Professor Smith were officers. 
Mr. Newlands proposed, in felicitous terms, the health of the Vice-Presidents, the Honorary Secretaries, and the Solicitor, coupling with the former the names of Dr. Adams and Mr. Cassal. The latter in reply spoke of the vast strides made by the analytical profession during the last few years, and said he thought they would look forward with confidence to the time when every member practising in the profession would be regarded as a valuable and honoured servant of the country.

Dr. Bernard Dyer, in responding to the toast of the Hon. Secretaries, referred to the work of the Society during the last nine years, and the labours of his predecessor, the late Mr. Wigner. He referred in cordial terms to the pleasant and harmonious way in which his friend Mr. Davies had, since Mr. Hehner's elevation to the chair, collaborated with him in the Secretarial work. He was sure they all regretted sincerely that Dr. Muter, who had served the Society as Vice-President for many years, and who was a familiar figure at their festive gatherings, was too unwell to be present on that occasion. He had received a letter from their honorary member and Past Vice-President, Dr. Vieth, who was at present resident in Germany, referring to the many happy hours he had spent with the members of the Society when attending their meetings in England, and the pleasure he experienced in receiving "The Avalyst" from time to time, that being the only paper he had read with interest since he had left the country.

Mr. Davies and Mr. Aubrey Rake having also suitably responded.

The Chairman proposed the toast of the "Guests," coupled with the name of Dr. James Bell.

Dr. Bell, in replying to the toast of the "Guests," said with regard to the President's cordial extension of the invitation to future dinners of the Society, he would be glad to respond at once and affirmatively to that invitation. He had felt a special interest in attending this dinner, for he naturally had very strong sympathies with professional chemists. He knew from experience the anxieties and difficulties they had to contend with, because those anxieties and difficulties corresponded with his own, and they were often great. He hoped that in the not distant future Public Analysts might be placed in a more satisfactory position than they at present occupied in the discharge of their local duties. Local authorities were often bodies whom it was almost impossible to satisfy, and he felt strongly that Public Analysts should be placed in a more independent position. The Society of Public Analysts had a splendid record. It had done a mass of excellent work, embodied in a series of admirable papers; it had devised many excellent processes of analysis, and it deserved the sincere thanks of the chemical profession generally. He wished it to be understood with regard to his official position that he was no conservative. He had followed every important process and investigated every promising method that had been brought forward under the auspices of the Society, and he had never hesitated, as soon as he was satisfied of their usefulness and their accuracy, to adopt such processes. His official position undoubtedly was sometimes a painful one. 
He regretted most deeply whenever he was obliged in any point to go against any Public Analyst in a matter of reference. He was glad to say that the great improvements in analytical work had, during recent years, relieved him of an important part of his own anxieties. Out of all the cases referred to him under the Sale of Food and Drugs Act during the last nine months, he was pleased to be able to say that there were only three cases in which he had felt himself obliged to differ from the opinions expressed by the Public Analysts. This, he thought, was extremely satisfactory and he believed that errors were now reduced almost to a minimum. He sincerely congratulated the Society on its progress and hoped it would continue, and as time went on he trusted that they would never have occasion to be apprehensive of the result of references to Somerset House. (Applause).

Dr. W. R. Smith proposed "The Analyst," and associated with it the name of its hardworking and energetic sub-editor, Dr. W. J. Sykes.

Dr. Sykes briefly returned thanks, and the proceedings shortly afterwards closed.

The pleasure of the evening was greatly enhanced by selections of vocal music contributed by Surgeon-Major Carte, Dr. Abraham, Mr. W. Bateman, Captain Watson, and other guests and members.

A special meeting of the Society was held at the Chemical Society's Rooms, Burlington House, on January 18th, for the discussion of the retiring President's (Mr. Otto Hehner's) Annual Address.

The Assay of Crude Carbolic Acid. G. Schacherl. (Zeits. osterr. Apoth. Ver., 1892, xxx. 794, through Chem. Zeit.)-The usual method of shaking out the phenols with caustic soda is liable to give inaccurate results, as a certain amount of resinous constituents and some neutral tar oil are also dissolved. The plan advocated is as follows :100 c.c. of the crude carbolic acid are taken if the sample be of poor quality, and 50 c.c. in the contrary case. The measured portion is then placed in a separating funnel and shaken out with 100 c.c. of caustic soda of sp. gr. 1·1, the alkaline liquid separated, and the shaking repeated two or three times with further quantities of 50 c.c. The separated liquid from the last extraction should give no oily drops when acidulated. The combined alkaline extract is then diluted with an equal volume of water, and distilled in a flask of about one litre capacity. When the distillate comes over free from oily drops, the removal of the neutral oils may be considered complete. The contents of the distilling flask are then allowed to cool, acidulated with hydrochloric acid and distilled again, using a large condenser. When the distillate, consisting of phenols accompanied by water, amounts to about 200 c.c., the operation is stopped, and the water separated from the phenols and returned to the distilling flask. The distillation is proceeded with and the collection of the phenols effected as before, the treatment being repeated until the whole of the phenols have come over. The last distillate, which should measure about 60 to 70 c.c., is supersaturated with salt, and the separated phenols read off and their volume added to that of the main quantity.

B. B. 